\title{
AFORISMO SOBRE O ECODESIGN ${ }^{1}$
}

Félix Guattari

Tradução: Vladimir Moreira Lima*

Revisão técnica: Cecília Campello do Amaral Mello**

Para que servem os especialistas da embalagem formal!? Dualidade matéria-forma out! Entre dois: substância enunciativa, processo autopoiético, natureza naturante, sem que haja aí matéria para Universais. Um tipo, o designer, se interpõe entre quem está olhando e a coisa manufaturada correndo o risco de ofuscá-la. De um lado, o jogo do marketing e da produção de massa. Desprezo. Mal-entendido. De outro, o jogo da emergência, do jamais visto, do inaudito. Aquém da relação objeto-sujeito: a enunciação; aquém das redundâncias dominantes, as formas-artifícios de um olhar armado - por que não? - de um profissional da maneira de olhar. Ritornelo: mas se o profissional, corpulento, for de matéria flexível e se molda conforme uma subjetividade serial qualquer?

Compromisso frouxo ou maiêutica do ser-para-a-forma? Design industrial ou design da singularidade? Quem quer que seja, aí inserido, o que está fazendo? Mas sua opinião é conhecida de antemão: é o já visto. Já que te dizem que o olhar se trabalha como as escalas ou, de preferência, como os estudos de estilo. De um lado, uma dessingularização generalizada, o desencantamento das formas, do outro, uma ressingularização precária, exposta aos ventos da moda. Amanhã, talvez, um design do "do it yourself’? Mas não, foi ontem!

O homem não vive só de fluxos. Ele se engata, se aglomera, se faz e refaz; ele fareja o odor de sua merda; ele destila mil ritornelos que o fazem estar aqui, ao abrigo do vidro, sonhando com o mar aberto. Mister Design, aí, faz signos. "Quanto mais puro é o elemento, mais rica é a combinação" (Gropius), mais o alisamento desterritorializa a matéria de expressão, melhor os universos de virtualidade se tornam capazes de restituir a complexidade. O design é um pouco como os preservativos. Mas em relação a qual AIDS?

Porque você havia acreditado que o virtual era uma coisa secundária, que ele era um nicho de não sei qual grande periferia do atual!? O design, veja você, tem a virtude de fazer vibrar o virtual no coração da interface usual - a cadeira, a mesa, o abridor de lata, o barbeador elétrico. “Objetos inanimados...” não

\footnotetext{
${ }^{1}$ Este aforismo e a entrevista que o acompanha foram publicados em Caravelles 2. 2ème quadriennale internationale de design, Lyon: Caravelles, 22 de junho de 1991.

* Doutor em Filosofia pela UFRJ (PPGF-IFCS) e professor da Universidade do Estado do Rio de Janeiro (IAp-UERJ).

E-mail: vladub77@gmail.com - Orcid: https://orcid.org/0000-0003-3189-0686

${ }^{* *}$ Professora do Instituto de Pesquisa e Planejamento Urbano e Regional da Universidade Federal do Rio de Janeiro.

E-mail: ceciliamellobr@gmail.com - Orcid: https://orcid.org/0000-0001-5920-6060
} 
possuem, talvez, uma alma animista mas, pelo menos, uma proto-alteridade. Tal como é, eu gosto, mas sei que ele dança com suas formas passadas... Você conhece a "aura" em preto e branco... E também dança com suas formas futuras, que batem na janela com seu bico de pássaro. Como o tempo passado!

Em suma, uma ética do virtual em um mundo onde a ontologia se pluraliza. Mas isso não seria honrar excessivamente esse design que, no entanto, permanece detestável sob vários ângulos?

Formas, sempre formas; eles só tem isso na boca! Mas e a sensibilidade, o afeto, a empatia!? Mesmo a publicidade compreendeu o jogo! A máquina design seria um artefato-interface entre o olhar observador, a carícia praticante, a singularidade maquínica. Ou seja, qualquer coisa de complicado como o desejo de hoje.

Se a pintura é o lied, o design é a ópera. Heterogêneses. As formas romanas de um poste de luz do pré-guerra. A era paleolítica do design. Talvez a ecosofia fará dele uma arte maior! A forma, o envelope, a maneira de fazer, não serão mais desperdícios desagradáveis, mas passarão ao coração do projeto produtivo. Atenção, senhor Hulot, você vai andar sobre a Vênus das Peles². Uma era pós-mídia, uma superação do sentido único. Não apenas eles "customizam" as cores de suas poltronas, mas programam também sua sociedade televisiva, através de uma multidão de canais, de bancos de dados e conexões telemáticas.

O design, a infância da arte. O dia em que não se poderá mais encontrar dois quartos de hotel semelhantes, duas escolas que tenham o mesmo cheiro, dois serviços psiquiátricos com as mesmas poltronas para os psicóticos debilitados... Que perspectiva para o turismo! Novamente algo para se ver. Para pensar, sentir. Viva o design conceitual.

\section{JÁJOGAMOS TODAS AS CARTAS DO VIRTUAL?}

\section{Entrevista com Félix Guattari ${ }^{3}$}

J.C.C - Retornemos a um conceito fundamental de sua obra, aquele de máquina, conceito que se junta a outras noções: "máquina concreta", "inconsciente maquínico"... ou ainda no texto que você propõe aqui, "máquina design", rompendo com a ideia convencional de máquina. O que podem produzir essas novas máquinas conceituais que você apresenta?

F.G - Trata-se de uma tentativa para - segundo uma expressão bastante feliz de P. Levy em um livro sobre "As tecnologias da inteligência" - levantar a "cortina de ferro ontológica" entre os mundos da objetividade e os universos da subjetividade. O conceito de máquina proposto visa a se instaurar numa

\footnotetext{
${ }^{2}$ Guattari se refere ao famoso ecologista francês Nicolas Hulot (1955-) e a obra de Sacher-Masoch intitulada $A$ Vênus das peles (1870) (Nota da tradução).

${ }^{3}$ Entrevista realizada no dia 29/01/91 por J.C Conesa e V. Lemarchands.

${ }^{4}$ Ed. de la Découverte, 1990.
} 
interface produtiva não apenas diante desse tipo de dualismo, mas também diante de uma concepção passiva da alteridade, alteridade dada como referência absoluta: "o grande Outro lacaniano". A máquina concebida fora de sua circunscrição tecnológica como máquina abstrata opera tanto no virtual quanto no atual; aliás, uma definição que não me pertence e que foi proposta por vários outros autores como, para começar, H. Maturana e F.J Varella ${ }^{5}$, é a ideia de que o que conta em uma máquina não é sua manifestação material mas o conjunto dos sistemas de relações, de interações, de retroalimentações que a constitui enquanto entidade com uma certa consistência; essa consistência será qualificada por Varela de autopoiética, ou seja, ela possui uma capacidade de reproduzir seus próprios elementos. Ele faz uma oposição entre autopoiese e alopoiese que, para mim, poderia ser substituída por uma certa concepção de consistência ontológica. Dito de outro modo, com a máquina nós não estamos diante de uma relação partes/extra-partes, e sim de sistemas que afirmam sua própria consistência, que afirmam através deles mesmos e que, ao mesmo tempo, desenvolvem certos campos de alteridade. Em outros termos, pode-se considerar que a máquina produz uma proto-subjetividade, uma proto-alteridade e que ela introduz no campo conceitual a associação de elementos de tomada de consistência ontológica com certas dimensões de precariedade, de finitude: a máquina é algo que tem um nascimento, que tem uma morte, que tem um desgaste e uma filogênese, ela tem antecedentes, ela terá sucessores. É, assim, uma entidade que nos coloca no coração de uma função de produção ontológica.

J.C.C - Justamente esse conceito de máquina que "nos coloca no coração de uma função de produção ontológica" parece, de uma certa maneira, se distanciar da noção de ética que aparecia no limiar da revolução industrial como um fundamento estruturante da realidade social: você pensa que esse princípio de ontologia que você maneja com as noções de "dessingularização generalizada/ressingularização precária” realiza uma análise realmente eficaz tanto quando se trata do design que, evidentemente, navega entre essas duas noções, quanto de todas as outras situações que ocorrem atualmente?

F.G. - Eu não penso que algum modelo possa dar conta da diversidade dos acontecimentos, dos estados de coisas que nos assolam. Vamos partir de um exemplo exterior, aquele da cultura rock. Por um lado, estamos lidando com um objeto da moda completamente integrado em relações do mercado capitalista - portanto há um tipo de submissão serial da subjetividade por parte daqueles que consomem essa música-rock. Mas, por outro lado, percebe-se que essa música pode desempenhar o equivalente daquilo que um psicanalista como Winnicott chamou de um objeto transicional na subjetividade. Ela pode constituir um solo de território existencial, território incorporal. Talvez, até mais: um território que faz com que a subjetividade de uma criança, de um adolescente, engate e se torne adjacente a um certo número de ritornelos temporais. Não é um objeto passivo, é um objeto que vai se consumir em grupo,

5 Autonomie et connaissance, Ed. Le Seuil, 1989. 
que tem uma história, é algo que pode marcar uma temporalidade; um grupo de adolescentes pode se delimitar em relação a um outro em função de suas escolhas, das últimas modas mutantes. Existe aí a possibilidade de organizar a si mesmo, de fazer um grupo... Assim, vemos a ambivalência perfeita de um objeto como o rock. Eu me pergunto se o design não participa de uma ambiguidade similar. De uma certa maneira, ele está preso nas relações de mercado, serializando um certo gosto, uma visão das coisas, uma moda, ideais de standing... e, por outro lado, ele pode fornecer elementos para a composição de uma ressingularização de um ambiente pessoal; ele marca certas estases da subjetividade que não podem ser abandonadas de qualquer forma a uma universalidade do campo do consumo; uma subjetividade que se esforça por talhar, definir sua visão de mundo nos territórios onde se encontra, aí onde se põe a existir. A perspectiva que eu proponho não é, então, aquela de uma alternativa brutal entre uma serialidade que seria o mal e uma ressingularização que seria o bem. Penso que existe um entrelaçamento entre os dois vetores. Para voltar ao design, me parece que seria necessário ser capaz de julgá-lo durante um período de tempo longo e numa perspectiva prospectiva. À medida que ele se apoia em materiais desterritorializados, materiais que estão cada vez mais articulados a um diagramatismo informático, é possível que ele ofereça uma saída dessas estases seriais e que o próprio design entre - tendo em vista algo que abordei em um outro domínio, quando evoquei uma era pós-mídia - em uma era pós-design. Nesse sentido, não é totalmente ficção científica imaginar que um consumidor possa encomendar a um produtor um certo tipo de objeto, algo que seja totalmente singular a si próprio, fornecendo as coordenadas, as formas, a definição para uma composição feita a partir de módulos informáticos muito simples que funcionariam como um teclado.

J.C.C - Um design telemático, então?

F.G - Um design telemático e informático. Nesse momento, haveria um tipo de junção entre a produção de massa, a criação que estaria na adjacência de uma criação estética e, sobretudo, a ressingularização de um certo ambiente que não seria uma simples personalização exterior, mas que permitiria produzir um ambiente singular de tal maneira que tornaria possível imaginar que cada residência, cada estabelecimento escolar, cada lugar público se encontraria ressingularizado, onde haveria, enfim, algo para ver, para visitar, sobretudo porque hoje estamos indo muito mais na direção de uma serialidade generalizada.

J.C.C - Você parece muito circunspecto quanto à função do designer, no sentido em que ele é apenas um intercessor entre o objeto manufaturado e o consumidor do qual não teríamos necessidade. Você prega uma relação direta, imediata, entre o objeto e o usuário como única saída possível para uma ressingularização do ambiente. Pode-se ter uma verdadeira solução para o problema da serialização do gosto nessa relação bipolarizada? Será que não nos encontraríamos, em tal sistema, em um mundo permanentemente em vias de se desfazer, onde não teríamos mais a possibilidade de uma "codificação", 
para usar um dos seus termos?

F.G - Me parece que longe de ir no sentido de uma posição bipolarizada como essa que você assinala, poderíamos sobretudo ir no sentido de uma complexificação multipolar. Não há uma, mas multiplicidades de interfaces. A função do designer, entre outras coisas, poderia ser a de produzir módulos dinâmicos de composição, abrindo campos de possibilidade para os consumidores, o que não interditaria em nada, nessa função de interface, de ser um criador. A questão é: nós poderíamos abrir a função da criação em um leque onde teríamos, de um lado, criadores em tempo integral, criadores profissionais e, do outro lado, criadores amadores. Seria preciso que todo mundo encontrasse seus filhos nessa evolução tecnológica. Entretanto, a ideia de se remeter a um profissional da criação e da moda nesse domínio do design, por exemplo - e poderíamos estender isso para outros domínios - me parece que deve ser revista com muita cautela. De início, porque o criador ele mesmo é prisioneiro das formações subjetivas que lhe excedem. Ele está banhado em restrições imaginárias e restrições simbólicas que lhe atravessam tanto quanto os demais consumidores. Ele procura, além disso, se colocar em sintonia com essas diferentes restrições. Enfim, penso que é preciso assumir um paradoxo que quer que, ao mesmo tempo, as funções de criação, as funções de trabalho intelectual, a inovação... dependam de especialistas, de profissionais e, simultaneamente, que essas mesmas funções se generalizarem, difundindo-se em todo corpo social. Há uma série de tensões, contradições, que não poderão ser superadas apenas depositando a responsabilidade nos especialistas e profissionais - como é o caso hoje - e, no outro lado, uma passividade total dos agenciamentos consumidores. Creio que é um esquema que pode ser remanejado de múltiplas formas.

V.L - Agora há pouco você falava de música. E se imaginássemos que em matéria de música nós pudéssemos consumir nossa própria música? Não haveria um efeito de fechamento, e não uma abertura tal qual foi possível desejar inicialmente, na preocupação em democratizar os fenômenos de criatividade solicitando às pessoas que desenhassem, que concebessem os objetos de seu ambiente?

F.G - Não, creio que sua posição é um pouco esquemática. De saída, já consumimos nossa própria música, programamos os canais de rádio que escutamos ou os discos que compramos. É possível quando vemos por exemplo a evolução da música minimalista - que existam módulos repetitivos articulados, que possam compor um programa personalizado. E mais, pode-se muito bem conceber a composição de um ambiente sonoro que não seja absolutamente antagônico com o fato de estarmos atentos às criações contemporâneas. Não há aí uma escolha unívoca. Eu penso, e repito, que a fase do abandono à serialidade e à passividade atual na relação de consumo dos objetos intelectuais ou objetos criativos não me parece de modo algum como algo irreversível ou definitivo. Ao contrário, a liberação do tempo de trabalho em decorrência das revoluções informáticas, robóticas, telemáticas levará, cada vez mais, os indivíduos e os grupos sociais a se colocar em posição de retomada da iniciativa, de reapropriação 
dos módulos sensíveis, intelectuais, afetivos, etc.

J.C.C - Mas em função de quais modelos? A partir do momento em que há a reapropriação por um certo número de grupos sociais, étnicos, culturais, de um certo número de elementos de criatividade, não seria necessário ver nessa vontade de reapropriação objetivos que se originam em uma cultura específica, raça ou grupo social? Você não teme, assim, que no lugar do efeito de emancipação, haja uma tendência a voltar para si mesmo, a um intimismo exagerado...? Se nos referimos, por exemplo, à Fête de la Musique, vemos muito bem que, em vez de liberar potenciais criativos, de favorecer a produção de músicas inauditas, nunca ouvidas, estamos indo na direção da reprodução de modelos arcaicos?

F.G - Não é disso que se trata. O problema é, sobretudo, mudar o tecido social. Voltamos aos ritornelos arcaicos quando se trata de simples celebração. Há toda uma concepção da cultura da celebração que, para mim, é muito perniciosa e patogênica. Assim, esse voltar para si mesmo, para os territórios fechados em si mesmo, a partir de arcaísmos culturais, não me parece corresponder ao movimento histórico atual. Veja, por exemplo, a evolução da música africana que, mantendo como base certos ritornelos, é capaz de pegar emprestado novos instrumentos e temas que fazem com que ela se irrigue a partir de músicas do mundo inteiro. Há uma fascinação pela escalada dos integrismos, sobretudo no mundo árabe. Dizem que se trata de uma nova forma de fascismo - o que corresponderia às suas preocupações - mas mesmo aí, se olharmos um pouco mais de perto, percebe-se que as coisas são mais complicadas. Em países do Magrebe, essa evolução não é evidente; existem muitos protestos das sensibilidades femininas que se recusam a ir nessa direção. Há uma teologia feminina do Alcorão que tende a reinterpretá-lo em um sentido não-integrista. Certamente, esse tipo de retorno, esse tipo de crispação sobre valores arcaicos e conservadores existem, fazem parte do desafio existente, mas, para mim, não há aí uma trajetória unilinear. Enfim, penso que nunca é o caso de modelos preestabelecidos, de arcaísmos, mas são sempre neoarcaímos que são articulados, irrigados por elementos de processualidade que os trabalham de diferentes maneiras.

J.C.C - Existe uma outra noção que aparece em seu trabalho, aquela de rizoma, que você opõe ao enraizamento. Você não acha que uma jovem disciplina como o design possa ter, às vezes, necessidade de raízes, obedecendo a elementos extremamente codificados tais como forma/função/standart/série, mas também de elementos menos demarcados com o intuito de contrapor-se a essas regras?

F.G - Você pode me precisar essa sua noção de standart?

J.C.C - É uma noção que faria com que voltássemos ao ano de 1907, no momento em que o Werkbund alemão engajou-se na produção de objetos que deveria impor e exportar um modelo social, cultural e 
moral forte, daí o apelo a uma máquina de guerra industrial eficaz (A.E.G, por exemplo). A noção de standartização dos produtos industriais residia na adaptação dos produtos e de suas imagens à ideologia da conquista.

F.G - Que haja a necessidade de novamente dar forma aos objetos seriais, produtos marcados pela função, o standart e cujas séries tendem mais ou menos a escapar, é uma coisa. Mas há ainda uma lei implacável que pesa sobre essa emancipação, aquela do equipamento capitalístico. Pois no final das contas, tudo isso só funciona, tudo isso só é sobrecodificado, na medida em que o design se insere em um certo tipo de mercado cuja finalidade, o mínimo que se pode dizer, não é ética, não é uma finalidade humana, nem uma finalidade ecológica de qualquer modo. Então, enquanto não houver uma explosão do mercado único capitalístico, enquanto não houver a promoção de um pluralismo de mercados, nada será verdadeiramente uma emancipação. Que haja um mercado mundial, certo, porque não, mas isso não quer dizer que o mercado das matérias primas que envolve os países do Terceiro Mundo deva ser complemente submetido a ele, ou que o mercado do petróleo, como vimos na guerra do Golfo, seja o regente obrigatório das relações internacionais. Isso não quer dizer que o mercado da pintura ou que o mercado da ópera, da ópera cômica, devam estar submetidos às mesmas regras que os mercados estatais. Podemos multiplicar os exemplos ao infinito. Que haja um mercado do gosto e da sensibilidade que seria aquele do design, com fronteiras, com zonas de passagem, interfaces com a criação artística, com domínios de ordem afetiva de composição de territórios existenciais, sem dúvida... mas nada disso é evidente. Não é a potência intrínseca ao movimento do design que pode resolver esse tipo de restrição. Aqui, é preciso introduzir um termo suplementar aqueles que você trouxe - forma/função/standard/série -, trata-se de restrições geopolíticas, geológicas, econômicas, demográficas, tecnológicas... Assim, que haja uma lógica, que haja uma estrutura, uma processualidade intrínseca a um movimento como esse do design, que haja coeficientes de liberdade internos que tendem a ser secretados por este movimento, eu não nego, mas isso não impede que cada uma de suas escolhas, cada uma de suas opções, se faça na encruzilhada de outras escolhas, de outras restrições e, portanto, esse movimento processual está ele mesmo articulado com posições ético-políticas que o transbordam por todas as partes. Desse modo, eu teria reservas sobre o fato de você projetar um design do design, se assim posso dizer, como sendo intrinsecamente portador de uma evolução, uma vez que ele é apenas parcialmente portador, sempre em articulação com outros sistemas.

J.C.C - De fato, eu penso que o design é menos portador do que tradutor de uma evolução: nós não percebemos que a história deixa mais traços da coisa manufaturada do que da máquina que a produziu. Para ir em outra direção, você emprega em seu texto uma fórmula extraordinária: "Atenção, senhor Hulot, você vai andar sobre a Vênus das Peles". O design é suficientemente rico para permitir a leitura do cotidiano em uma dimensão de subversão e perversidade? 
F.G - O design se encontra, manifestadamente, em sua fase atual, demasiadamente asseptizado, ancorado em uma visão etérea das coisas, em um puro formalismo e, por outro lado, há uma artista japonesa, que também é doente mental, Yayoi Kusama, que faz instalações e trabalha com materiais de tipo design, materiais modernos com os quais ela produz um mundo de singularidade, de complexidade e de “regressão" totalmente extraordinário.

J.C.C - De um modo geral, o que você pensa dos artistas que utilizam objetos do cotidiano, tais como Lavier, Koons... O que você pensa desse mundo da simulação que duplica o real?

F.G - Não existe o Real, assim como não há o Imaginário e o Simbólico. Existem reais. Passamos de um nível de realidade a outro nível de realidade. Então, não há desrealização, há desterritorialização através da produção de estratos de realidade, estratos de imaginários, quando temos objetos desviados. Às vezes, vemos isso com a arte conceitual, o desvio enunciativo é tão mais brutal à medida que o objeto referido é o mais banal, porque há uma espécie de imensa aceleração do questionamento: o que é isso que me acontece? O que querem de mim? O que eu vou fazer diante desse objeto que me acompanha todos os dias? Existe, assim, a promoção de um objeto estético desterritorializado que, se for capaz de atravessar as redundâncias dominantes, possui um efeito devastador que abalará as próprias bases da subjetividade.

J.C.C - Em seu texto, você joga ao mesmo tempo com a responsabilidade do designer, visto como uma espécie de mercenário que se impõe como um profissional da maneira de ver, e com a desculpabilização do design considerado sob o prisma das circunstâncias atenuantes. Sua reflexão procede a partir da indiferença em relação ao design ou você espera muito dessa disciplina?

F.G - É uma reflexão que eu havia desenvolvido, sobretudo, pensando o caso dos publicitários, e que aparece como uma incidência dessa reflexão inicial. Mas de uma maneira geral, creio que o inimigo número um é sempre a culpabilidade, pois ela é composta de tal maneira que sempre nos enganamos quanto ao alvo. Assim, vamos na direção de uma responsabilização onde, precisamente, existem causalidades múltiplas e nenhuma responsabilização pode ser circunscrita, o que implicaria uma impossibilidade de apreender onde estão as matérias de opção. Desse modo, o primeiro movimento, a respeito dos publicitários e dos designers, seria o de dizer: "Bom, façam o que vocês fazem, tal como estão inseridos nos dispositivos de produção, não vemos como vocês poderiam fazer diferente". O que vou dizer pode parecer provocador, mas tenho um pouco o mesmo sentimento diante dos físicos que acusamos de ser os responsáveis pelos holocaustos atômicos... - ou a gente retoma o conjunto do processo, que nos leva até Arquimedes, ou aceitamos tudo. E, entretanto, quando nos livramos da culpabilidade, encontramos a problemática dos níveis de escolhas reais, das opções, das mutações éticas; 
nesse ponto, não é mais o caso de uma responsabilidade relacionada a normas transcendentes, ou a efeitos finalizados bem localizados, mas são todas as hesitações, os medos, as covardias e os recuos diante dos processos maquínicos em relação aos quais nós nos encontramos na adjacência que está em questão: será que jogamos bem todas as cartas do virtual? É por isso que falo de uma ecologia do virtual ou de uma ecosofia. É algo que não dá para ensinar, não há pedagogia e, no entanto, apreende-se bem no domínio estético. Quando se analisa um autor, a partir de certos momentos, entendemos quando ele se acovardou, cedeu, deixou-se levar; vê-se bem, ao contrário, outros artistas que não se furtaram ao risco de massacrar a própria obra. Penso em Kafka, que preferiu rasurar e recortar toda sua obra porque estava atormentado, obcecado pelo respeito a um certo rigor, pela busca das linhas de fuga, das virtualidades que o habitavam.

J.C.C - Você desconfia do que é maior e prefere o que é menor...

F.G - Você certamente possui seus designers menores!

V.L - Você sublinhou de maneira bastante ácida a falta de maturidade do designer diante das responsabilidades que se supõe que ele deveria ter enquanto criador. Ora, ainda que um artista possa intervir sobre o mundo real e permanecer crítico, é muito difícil desviar uma produção industrial antes que ela chegue no mercado. Você acha que um designer poderia ser crítico de antemão, isto é, antes que a produção chegue ao mercado?

F.G - Se tomarmos o caso dos aviões, dos automóveis, o designer age sobre uma série de definições, restrições, portanto sua intervenção é setorial, parcial, desterritorializada. É por isso que, ainda que eu proponha uma definição da máquina que possa dar conta de máquinas tão diversas, como uma máquina técnica, uma máquina teórica, uma máquina estética, uma máquina desejante - idealmente, porque é muito difícil - ainda assim creio que um design abstrato, conceitual, teria que dar conta de coisas tão diversas, inclusive um design que vai lidar com um barbeador elétrico ou com definições de espaços urbanos complexos, ou mesmo, por que não, com moléculas químicas ou com módulos cognitivos, tal como o matemático que pretende que o critério de escolha entre várias demonstrações seja, frequentemente, apenas uma questão de elegância. É como se houvesse uma função de design matemática. Assim, penso que não é preciso ficar com o nariz colado no objeto. Existe um trabalho da subjetividade através das formas visuais, sonoras, lógicas, afetivas, todas as gestaltung? As formas caem do céu? Elas são universais diante dos quais é preciso se ajoelhar e rezar ou, ao contrário, há manipulação, inteligência, trabalho, bricolagem, inventividade? A essência do design estaria, talvez, aí: uma raiz éticopragmática. É preciso dar minha opinião? E o que seria a opinião nesse caso? A subjetividade, nesse contexto, é processo de produção ou recepção passiva de formas transcendentes?

V.L - Grosso modo, o design é útil? 
F.G - Você introduziu uma finalidade, então, desse modo, não, pois se é útil, deixa de ser processual. O design é fundamentalmente inútil, como o artista, como todas as coisas importantes são um excedente, um luxo. Não é útil fazer um objeto segundo o design, podemos fazer com que um objeto seja funcional e parar por aí, mesmo a publicidade podemos perguntar se ela é útil. Existe essa coisa abominável do um por cento para a arte que me parece terrível enquanto princípio, ao passo que o design seria, de certa forma, cem por cento de criação artística, em todos os gestos da vida, em todas as ações produtivas. Não é uma questão de qualidade de vida, mas de qualidade de ser, uma questão de qualidade de produção ontológica.

J.C.C - Não existem objetos de design absolutamente perfeitos feitos em série que não sejam desvalorizados por isso. A sociedade tecnológica não secreta objetos em série pensados e bem pensados para o grupo? A própria guerra do golfo não evidenciou verdadeiros objetos da sociedade informática pós-industrial? Mesmo sabendo que a guerra é uma situação regressiva, bárbara, não poderíamos, cinicamente, enxergá-la como uma espécie de exposição universal?

F.G - Uma grande festa do design! Eu tomo partido de posições progressistas mas, por outro lado, não creio que o movimento da história seja progressista. Eu não creio mais no voluntarismo progressista. Já faz muito tempo que eu acreditei ter descoberto uma lei fundamental da história diante da qual todas as outras leis se apagam, perdem sua credibilidade. Eu a formularia assim: diante de qualquer situação histórica, se listarmos dez soluções, indo da mais racional até a mais absurda, será sempre a mais estúpida que advém. A regressão, a estupidez, o amor à besteira, rolar na lama em cima de uma série de argumentações inconsistentes, não é algo que desaparece com o passar do tempo, é algo sempre pronto a retornar. A subjetividade é habitada por uma potência de caos que não é a potência de uma pulsão de morte, como Freud havia formulado, é uma apreensão do ser para si, em uma espécie de propensão totalitária, devastadora. Na psiquê americana, tudo isso, somos nós, o mundo, a lei, a ordem... uma peça única, um só golpe, há uma espécie de confusão mental invasiva como na paranoia, em que toda racionalidade se apaga. O mundo da maior complexidade no domínio das ciências, da tecnologia, das artes, é habitado por essa virtualidade do caos apropriador.

V.L - Hoje, na ótica da guerra, parece que, cada vez mais, estamos distante de atingir as respostas para os problemas do terceiro mundo. O que você pensa das atitudes, como aquela de José Zanine por exemplo, que parecem não estar ligadas ao design, tendo em vista que não existem novos materiais, nem estilo, nem marketing... mas que podem ser o esboço de uma terceira via, da mítica terceira via?

F.G - Eu penso que o grande perigo é aquele da constituição de um mercado econômico capitalístico 
planetário que devasta os territórios existenciais, que abandona totalmente o indivíduo aos fluxos mundiais de troca em relação aos quais ele não pode se recompor. Esses territórios existenciais são de diferentes níveis. Aquele do ambiente mais imediato, aquele da ecologia social, aquele de uma ecologia mental, de uma ecologia ambiental. Eles se colocam também no nível da etnia, dos conjuntos nacionais e regionais. O que não quer dizer que é preciso fazer com que as entidades vivam em autarquia, cortadas de todas as trocas exteriores. O problema está em conseguir articular, de maneira rizomática e não arborescente, mercados heterogêneos. Por exemplo, para um país do terceiro mundo que também é uma grande potência industrial como o Brasil, nota-se que se colocam problemas urbanísticos extremamente locais ao nível das favelas... ao lado de empreendimentos industriais que são grandes concorrentes no mercado mundial. Existem vários tipos de mercados intermediários para se preservar, como o mercado ecológico que diz respeito à floresta amazônica. Todos esses mercados devem funcionar como interfaces maquínicas que preservam seus próprios níveis de especificidade. Sob o pretexto de que há um mercado da madeira, que não se desvaste o pulmão amazônico; sob o pretexto de que há um mercado imobiliário, que não se destrua as favelas em não importam quais condições. É essa plurivalência dos mercados ou territórios existenciais que me parece essencial promover. Correlativamente, seria preciso redefinir o conceito de poder de Estado, que não pode ser apenas uma peça, um simples retransmissor da economia do Capitalismo mundial integrado, mas que deve ser o lugar de uma articulação entre esses diferentes territórios existenciais. Ao mesmo tempo um lugar de abertura parcial e de fechamento contingente; regulação entre os níveis múltiplos e contraditórios - o que implica ultrapassar a democracia consensual e ir em direção à promoção de sistemas de concertação dissensual.

Recebido em: 02de abril de 2021. Aprovado em: 03 de maio de 2021. 